\title{
Synthesis of Pimarane-type Diterpenes from Constituents of Copaiba Oil.
}

\section{Daiane Cristina Sass (PG) ${ }^{a^{*}}$ Vladimir C. G. Heleno (PQ) ${ }^{\mathbf{b}}$; Aline Nazaré Silva (PG) Simone Cavalcante Silva (PG) ${ }^{a}$; Mauricio Gomes Constantino (PQ) .}

\author{
${ }^{a}$ Departamento de Química, FFCLRP-USP; ${ }^{b}$ Núcleo de Pesquisas em Ciências Exatas e Tecnológicas, \\ UNIFRAN.
}

*Tel: +55 (16)-36023879 daiane-sass@pg.ffclrp.usp.br

Keywords: Pimaranes, Diterpenes, Copalic acid.

\section{INTRODUCTION}

Pimarane-type diterpenes, such as pimara8,15-diene (1) and pimaradienoic acid (5) (figure 1), are mainly isolated from conifer oleoresin. This class of compounds has shown interesting biological activities, e.g. analgesic, anti-tumor, antiinflammatory, vasorelaxant, antimicrobial activities, anti-Alzheimer and antioxidant effects. ${ }^{1}$ Due to the importance of this class, several research groups have already proposed total synthesis of those substances.

Figure 1. Pimarane-type diterpenes
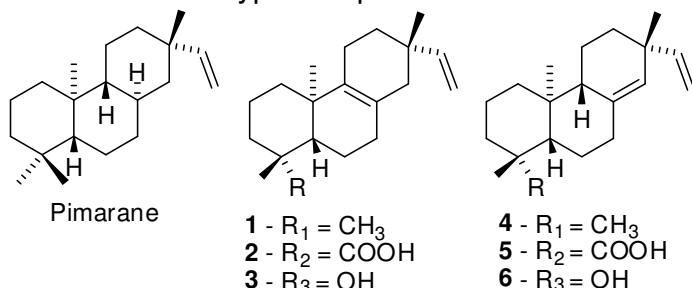

Thus, we decided to study the synthesis of these compounds from two main constituents of Copaiba oil, copalic acid (7) and ent-agathic acid (8) (figure 2).

Figure 2. Constituents of Copaiba oil<smiles>CC1=C(C(=O)O)C2CCC3C(C)(C)CCC[C@]3(C)C2CC1</smiles><smiles>CC1=C(C(=O)O)C2CCC3C(C)(C)CCC[C@]3(C)[C@@H]2CC1</smiles>

\section{RESULTS AND DISCUSSION}

Considering the structures of the compounds in figures 1 and 2 , we see that the pimaranes could be obtained from derivatives of the acids 7 and 8 (e.g. compound 9) (scheme 1), through an acid catalyzed elimination for formation of carbocation $\mathbf{1 0}$ and subsequent rearrangement with cyclization to produce 11. The elimination of a proton could give the pimaranes systems (figure 1).

\section{Scheme 1.}

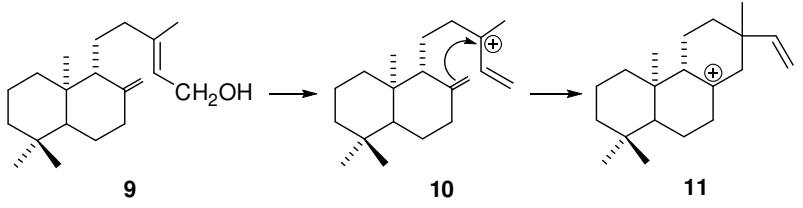

We started our studies with the copalic acid (7). Firstly it was reduced with $\mathrm{LiAlH}_{4}$ in THF to its corresponding alcohol (copalol 9), with a yield of 90\% (scheme 2). Subsequently the copalol (9) was treated with a solution containing acetic acid, sulphuric acid and water at $50^{\circ} \mathrm{C},{ }^{2}$ quenching the reaction right after complete consumption of starting material. As shown in scheme 2, we can obtain the pimara-8,15-diene (1) and its epimer 12, with yields of $32 \%$ and $28 \%$ respectively.

Scheme 2.

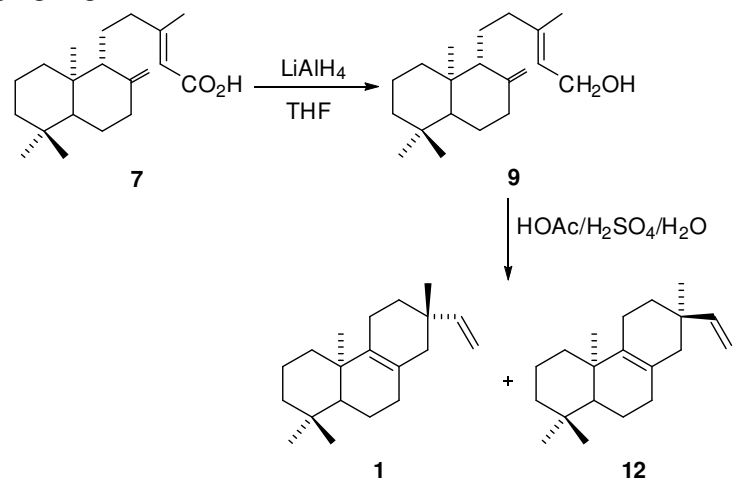

\section{CONCLUSION}

The acid catalyzed rearrangement of the more abundant copalol-type structures can produce pimarane-type diterpenes with reasonable yields. We intend to realize an extensive study of several reaction conditions in order to obtain better yields and, if possible, some others structures as compound 5 .

\section{ACKNOWLEDGEMENTS}

FAPESP, CAPES and CNPQ.

\section{REFERENCES}

1 Jung, H. A. et al. Arch Pharm Res 2009, 32, 1399-1408.

2 .McCreadie, T. et al. J. Chem. Soc. 1971, 312-316. 